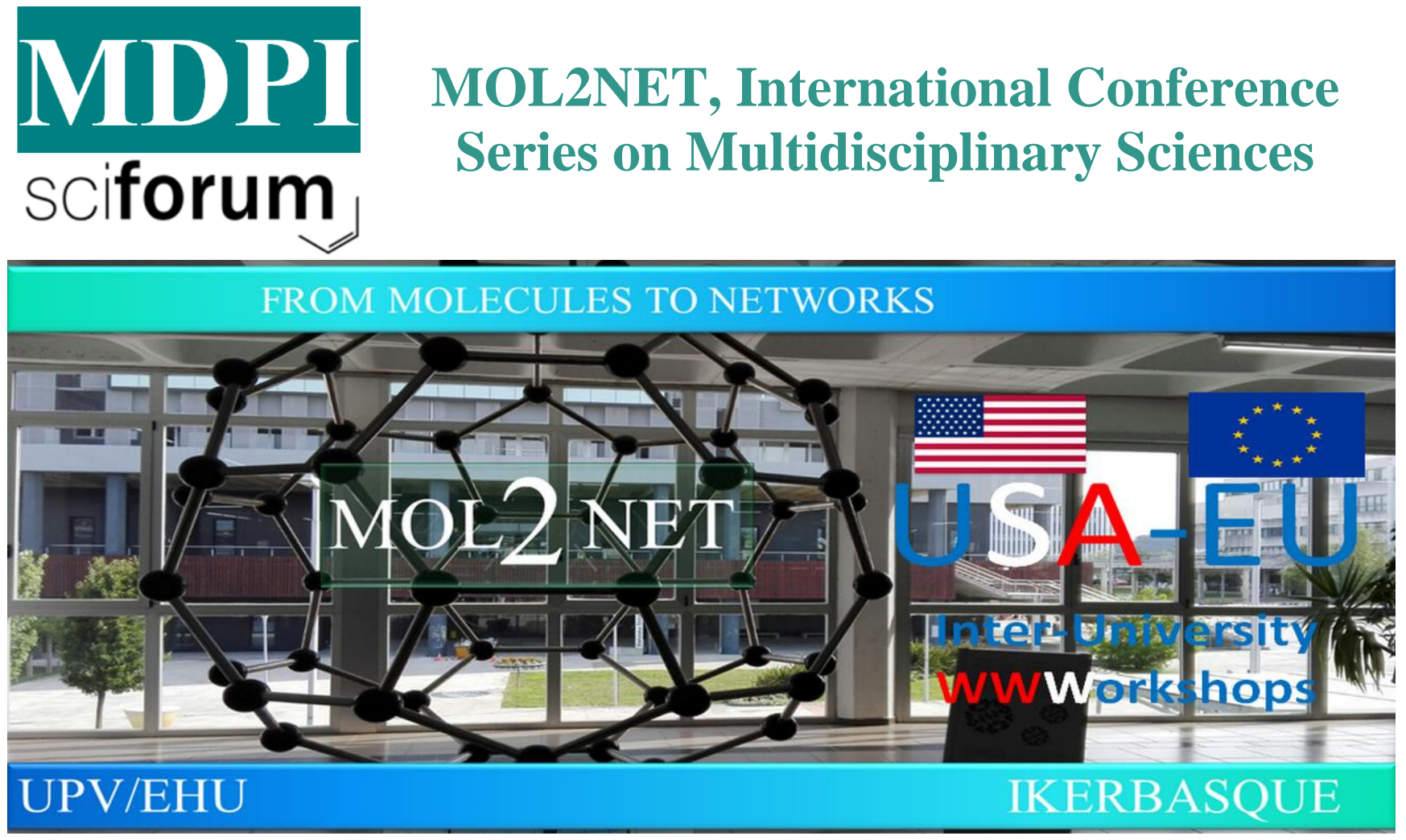

\title{
Enhanced Defluoridation from Aqueous Solutions using Zirconium - coated Pumice in Fixed-bed Column Systems
}

Wondwosen Sime Geleta $1^{a, b}$, Esayas Alemayehu $2^{c}$, Bernd Lennartz $3^{b}$

${ }^{a}$ School of Chemical Engineering, Jimma Institute of Technology, Jimma University, P.O.Box 378,

Jimma, Oromia, Ethiopia; wondeto@gmail.com

${ }^{b}$ Faculty of Agricultural and Environmental Sciences, University of Rostock, Justus-Von-Liebig-Weg 6, 18059 Rostock, Germany; bernd.lennartz@uni-rostock.de

${ }^{c}$ Faculty of Civil and Environmental Engineering, Jimma Institute of Technology, Jimma University, P.O.Box 378, Jimma, Oromia, Ethiopia; esayas16@yahoo.com 


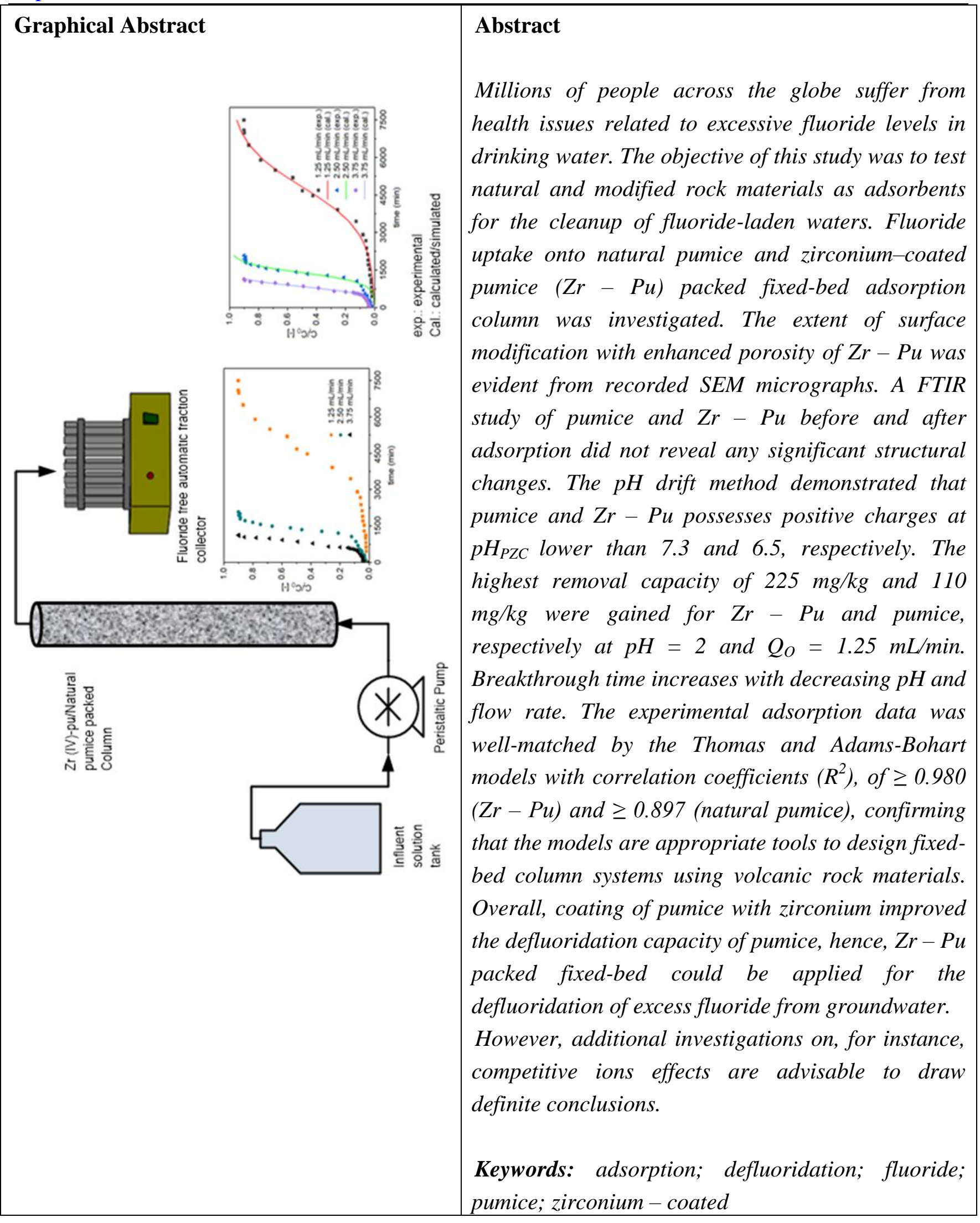

\section{Introduction}

Millions of people across the globe are exposed to high fluoride levels in drinking water. Consumption of fluoride in low concentration $(<1.0 \mathrm{mg} / \mathrm{L})$ has positive effects as fluoride is an essential micronutrient necessary for the development of bone and dental enamel [1], however, it leads to the development of fluorosis if it is consumed above the allowable limit (>1.5 mg/L) [2]. Because of the 
severe health consequences related to fluorosis, water purification techniques such as reverse osmosis [3], chemical precipitation [4], electrocoagulation [5], coagulation sedimentation [6], ultrafiltration [7], electrodialysis [8], ion exchange [9], and adsorption [10], are used for the defluoridation of groundwater. Adsorption is still among the most widely employed methods, because of its high efficiency, low cost, ease to use, and simple design of treatment units employing adsorption [11,12]. Efficient and low-cost water defluoridation materials are very crucial for underdeveloped countries. Pumice is among the most encouraging and low-priced naturally available materials that have been broadly examined and applied for pollutant removal in water treatment [13,14]. Surface-modified pumice might be even a more effective adsorbent for water contaminants [15]. Pumice is abundant in the Ethiopian Main Rift where fluorosis from a high fluoride level is common. Therefore, in this study, we investigated and evaluated experimental parameters for water defluoridation with natural pumice and zirconium - coated pumice $(\mathrm{Zr}-\mathrm{Pu})$ in packed columns.

\section{Materials and Methods}

Up-flow adsorption experiments were performed to investigate defluoridation from aqueous solutions onto natural pumice and $\mathrm{Zr}-\mathrm{Pu}$. Repeatedly washed and dried pumice was crushed to a particle size of $0.075-0.425 \mathrm{~mm}$ and $0.1 \mathrm{M} \mathrm{ZrOCl}_{2} .8 \mathrm{H}_{2} \mathrm{O}$ was used in the coating of zirconium onto pumice, with a slight modification of the method used by Salifu et al. [16]. The $\mathrm{Zr}-\mathrm{Pu}$ was washed repeatedly with deionized water to remove unadsorbed zirconium and impurities, dried, and stored for subsequent use. XRD, SEM, and FTIR were used to determine the crystalline structure, morphologies, and the functional groups of pumice and $\mathrm{Zr}-\mathrm{Pu}$ before and after adsorption, respectively, while XRF and ICP-OES were employed to determine the oxide and elemental content respectively, of pumice. The $\mathrm{pH}$ point of zero charge $\left(\mathrm{pH}_{\mathrm{PZC}}\right)$ of the adsorbent was determined by the $\mathrm{pH}$ drift method and the batch equilibrium technique. A weighted amount of the adsorbent was packed uniformly into a column with an inner diameter of $8.1 \mathrm{~cm}$ and a height of $10 \mathrm{~cm}$ as a fixed-bed absorber. A peristaltic pump was used to pump the fluoride solution into the fixed bed and an automatic fraction collector was employed to collect the effluent. Ion chromatography was used to measure the fluoride concentration in the effluent samples. We examined the effects of initial solution $\mathrm{pH}(2,4$, and 6$)$ and flow rate $(1.25,2.50$, and $3.75 \mathrm{~mL} / \mathrm{min}$ ) on the shape of breakthrough curves and the amount of fluoride removed at constant initial fluoride level $(10 \mathrm{mg} / \mathrm{L})$ and fixed-bed column height $(10 \mathrm{~cm})$.

\section{Results and Discussion}

The XRD analysis revealed that the amorphous phase/s is dominant enabling good accessibility for fluoride. The SEM micrographs obtained for $\mathrm{Zr}-\mathrm{Pu}$ before and after adsorption showed that the surface of natural pumice was modified. The surface of $\mathrm{Zr}-\mathrm{Pu}$ before adsorption is dense and larger pores were noticed. The dense surface may be attributed to the coating of the exterior surface of pumice with zirconium, while the formation of pores origins from the removal of water-soluble compounds and dust by washing it repeatedly with deionized water. Sepehr et al.[17] reported the improvements of porous structure and adsorption for surface modification of pumice. The surface of $\mathrm{Zr}$ - Pu after adsorption exhibited a large but limited number of heterogeneous channels. This may be owing to the slight reduction in particle structure of natural pumice during modification and adsorption processes. Compatible remarks were also drawn in the previous study [18]. The FTIR spectra remained almost unchanged for pumice and $\mathrm{Zr}$ - Pu before and after adsorption and consistent with a previously 
reported study [19]. The XRF and ICP-OES measurements showed that $\mathrm{Si}, \mathrm{Fe}$, and $\mathrm{Al}$ are major oxides and elemental content of pumice. The values of $\mathrm{pH}_{\mathrm{PZC}}$ were measured to be 7.3 for pumice and 6.5 for $\mathrm{Zr}-\mathrm{Pu}$. Breakthrough times were delayed and the treated water volume was greater at a lower $\mathrm{pH}$ and flow rate. The maximum defluoridation capacity was $110 \mathrm{mg} / \mathrm{kg}$ for pumice and $225 \mathrm{mg} / \mathrm{kg}$ for $\mathrm{Zr}-\mathrm{Pu}$ at initial solution $\mathrm{pH}=2$ and influent flow rate $\left(\mathrm{Q}_{\mathrm{O}}\right)=1.25 \mathrm{~mL} / \mathrm{min}$. The Thomas and Adams-Bohart models very well depicted the experimental data with correlation coefficients of $\geq 0.980$ for $\mathrm{Zr}-\mathrm{Pu}$ and $\geq 0.897$ for natural pumice.

\section{Conclusions}

In this work, the fluoride uptake performance of the natural and $\mathrm{Zr}-\mathrm{Pu}$ packed fixed-bed column system was investigated. The ICP-OES and XRF analysis revealed that the adsorbent does not contain any harmful substances which could possibly be released in a flow-through set-up. Fluoride adsorption onto $\mathrm{Zr}-\mathrm{Pu}$ and pumice was $\mathrm{pH}$ and input flow rate dependent. The maximum uptake capacity of fluoride onto zirconium-coated pumice was $225 \mathrm{mg} / \mathrm{kg}$ (more than twice the capacity of pumice: 110 $\mathrm{mg} / \mathrm{kg}$ ), at $\mathrm{pH} 2$ and input flow rate of $1.25 \mathrm{~mL} / \mathrm{min}$. A fixed-bed column of $265 \mathrm{~g} \mathrm{Zr}-\mathrm{Pu}$ can generate more than $4 \mathrm{~L}$ of treated water with an acceptable fluoride level of $<1.5 \mathrm{mg} / \mathrm{L}$. This study demonstrated that the coating with zirconium doubled the adsorption capacity of pumice, making it a very efficient adsorbent for defluoridation.

Conflict of Interest: The authors declare no conflict of interest.

Acknowledgments: The first author is very thankful to the German Academic Exchange Service (DAAD) for providing the scholarship during the study.

\section{References}

1. Ye, Y.; Yang, J.; Jiang, W.; Kang, J.; Hu, Y.; Ngo, H. H.; Guo, W.; Liu, Y. Fluoride Removal from Water Using a Magnesia-Pullulan Composite in a Continuous Fixed-Bed Column. J. Environ. Manage. 2018, 206, 929-937, doi: 10.1016/j.jenvman.2017.11.081.

2. J. Fawell, K. Bailey, J. Chilton, E. Dahi, L. F. and Y. M. Fluoride in Drinking-Water; World Health Organization (WHO) with IWA Publishing: London, UK, 2006; ISBN 9781900222969.

3. Shen, J.; Schäfer, A. I. Factors Affecting Fluoride and Natural Organic Matter (NOM) Removal from Natural Waters in Tanzania by Nano Filtration/Reverse Osmosis. Sci. Total Environ. 2015, 527-528, 520-529, doi: 10.1016/j.scitotenv.2015.04.037.

4. Huang, H.; Liu, J.; Zhang, P.; Zhang, D.; Gao, F. Investigation on the Simultaneous Removal of Fluoride, Ammonia Nitrogen and Phosphate from Semiconductor Wastewater Using Chemical Precipitation. Chem. Eng. J. 2017, 307, 696-706, doi: 10.1016/j.cej.2016.08.134.

5. López-Guzmán, M.; Alarcón-Herrera, M. T.; Irigoyen-Campuzano, J. R.; Torres-Castañón, L. A.; Reynoso-Cuevas, L. Simultaneous Removal of Fluoride and Arsenic from Well Water by Electrocoagulation. Sci. Total Environ. 2019, 678, 181-187, doi: 10.1016/j.scitotenv.2019.04.400.

6. Gan, Y.; Wang, X.; Zhang, L.; Wu, B.; Zhang, G.; Zhang, S. Coagulation Removal of Fluoride by Zirconium Tetrachloride: Performance Evaluation and Mechanism Analysis. Chemosphere 2019, 218, 860-868, doi: 10.1016/j.chemosphere.2018.11.192.

7. Liu, C. C.; Liu, J. C. Coupled Precipitation-Ultrafiltration for Treatment of High FluorideContent Wastewater. J. Taiwan Inst. Chem. Eng. 2016, 58, 259-263, doi: 10.1016/j.jtice.2015.05.038.

8. Majewska-Nowak, K.; Grzegorzek, M.; Kabsch-Korbutowicz, M. Removal of Fluoride Ions by Batch Electrodialysis. Environ. Prot. Eng. 2015, 41, 67-81, doi: 10.5277/epe150106. 
9. Li, Q.; Wang, B.; Li, W.; Wang, C.; Zhou, Q.; Shuang, C.; Li, A. Performance Evaluation of Magnetic Anion Exchange Resin Removing Fluoride. J. Chem. Technol. Biotechnol. 2016, 91, 1747-1754, doi: 10.1002/jctb.4764.

10. Sarkar, C.; Basu, J. K.; Samanta, A. N. Experimental and Kinetic Study of Fluoride Adsorption by Ni and Zn Modified LD Slag Based Geopolymer. Chem. Eng. Res. Des. 2019, 142, 165-175, doi: 10.1016/j.cherd.2018.12.006.

11. Teng, S. X.; Wang, S. G.; Gong, W. X.; Liu, X. W.; Gao, B. Y. Removal of Fluoride by Hydrous Manganese Oxide-Coated Alumina: Performance and Mechanism. J. Hazard. Mater. 2009, 168, 1004-1011, doi: 10.1016/j.jhazmat.2009.02.133.

12. Banerjee, A. Groundwater Fluoride Contamination: A Reappraisal. Geosci. Front. 2015, 6, 277284, doi: 10.1016/j.gsf.2014.03.003.

13. Geleta, W. S.; Alemayehu, E.; Lennartz, B. Volcanic Rock Materials for Defluoridation of Water in Fixed-Bed Column Systems. Molecules 2021, 26, 977:1-977:20, doi: 10.3390/molecules26040977.

14. Mekonnen, D. T.; Alemayehu, E.; Lennartz, B. Adsorptive Removal of Phosphate from Aqueous Solutions Using Low-Cost Volcanic Rocks: Kinetics and Equilibrium Approaches. Materials (Basel). 2021, 14, 1312, doi: 10.3390/ma14051312 Academic.

15. Asere, T. G.; Verbeken, K.; Tessema, D. A.; Fufa, F.; Stevens, C. V.; Du Laing, G. Adsorption of As(III) versus As(V) from Aqueous Solutions by Cerium-Loaded Volcanic Rocks. Environ. Sci. Pollut. Res. 2017, 24, 20446-20458, doi: 10.1007/s11356-017-9692-z.

16. Salifu, A.; Petrusevski, B.; Ghebremichael, K.; Modestus, L.; Buamah, R.; Aubry, C.; Amy, G. L. Aluminum (Hydr) Oxide Coated Pumice for Fluoride Removal from Drinking Water: Synthesis, Equilibrium, Kinetics and Mechanism. Chem. Eng. J. 2013, 228, 63-74, doi: 10.1016/j.cej.2013.04.075.

17. Sepehr, M. N.; Sivasankar, V.; Zarrabi, M.; Senthil Kumar, M. Surface Modification of Pumice Enhancing Its Fluoride Adsorption Capacity: An Insight into Kinetic and Thermodynamic Studies. Chem. Eng. J. 2013, 228, 192-204, doi: 10.1016/j.cej.2013.04.089.

18. Liang, Z.; Ni, J. Improving the Ammonium Ion Uptake onto Natural Zeolite by Using an Integrated Modification Process. J. Hazard. Mater. 2009, 166, 52-60, doi: 10.1016/j.jhazmat.2008.11.002.

19. Sepehr, M. N.; Amrane, A.; Karimaian, K. A.; Zarrabi, M.; Ghaffari, H. R. Potential of Waste Pumice and Surface Modified Pumice for Hexavalent Chromium Removal: Characterization, Equilibrium, Thermodynamic and Kinetic Study. J. Taiwan Inst. Chem. Eng. 2014, 45, 635647, doi: 10.1016/j.jtice.2013.07.005. 